\section{CONCENTRACIÓN INADECUADA DE CLORO RESIDUAL LIBRE EN AGUA DE HOGARES DE LIMA METROPOLITANA, 2016}

\author{
INADEQUATE FREE RESIDUAL CHLORINE \\ CONCENTRATIONS IN WATER OF HOMES IN \\ LIMA METROPOLITANA, 2016
}

\author{
Guido Bendezu-Quispe ${ }^{1, a}$, Cynthia Whuking-Zea ${ }^{2, b}$, \\ Paola Medina-Molina ${ }^{2, b}$, Andres Maruy-Yumi ${ }^{2, b}$, \\ Benjamin Namuche-Marín ${ }^{2, b}$
}

Sr. Editor. El acceso a agua segura es fundamental para preservar la salud de las personas, siendo reconocido como un derecho humano esencial por las Naciones Unidas en el $2010^{(1)}$. En Perú, el Reglamento de la Calidad del Agua para Consumo Humano del Ministerio de Salud (2010), señala que el agua de consumo debe estar exenta de bacterias coliformes como Escherichia coli, virus, helmintos, quistes u ooquistes de protozoarios patógenos, y en caso de bacterias heterotróficas debe tener menos de $500 \mathrm{UFC} / \mathrm{ml}$ a $35^{\circ} \mathrm{C}{ }^{(2)}$. Para el logro de esta idoneidad, los proveedores de agua deben asegurar un nivel de cloro residual no menor de $0,5 \mathrm{mgL}^{-1}$ en cualquier punto de la red de distribución (2).

La cloración del agua es un método costo-efectivo para el control de enfermedades como el cólera, disentería, tifoidea, polio, entre otras, que anualmente causan más de 500000 muertes por enfermedades diarreicas en el mundo (3). Teniendo en cuenta la importancia del acceso a agua segura, se realizó un análisis secundario de la Encuesta Nacional de Hogares (ENAHO) 2016 de los resultados obtenidos de la evaluación de los niveles de cloro residual libre en la muestras de agua tomadas de los hogares ${ }^{(4)}$. Se estimó el porcentaje de hogares con abastecimiento de agua por red pública y sus niveles de cloro residual considerando los factores de expansión y diseño muestral de la ENAHO 2016. Finalmente, se condujo un análisis de densidad Kernel de los conglomerados de hogares con conexión a la red pública de abastecimiento de agua sin niveles adecuados de cloro en Lima Metropolitana. Se utilizó el paquete estadístico Stata 14.2 (StataCorp LP, College Station, TX, USA), para caracterizar los hogares con abastecimiento de agua con

\footnotetext{
Universidad Peruana Cayetano Heredia. Lima, Perú.

Universidad Científica del Sur. Lima, Perú.

Médico cirujano; ${ }^{\mathrm{b}}$ Estudiante de Medicina Humana

Recibido: 02/05/2018 Aprobado: 06/06/2018 En línea: 03/07/2018
}

Citar como: Bendezu-Quispe G, Whuking-Zea C, Medina-Molina P, MaruyYumi A, Namuche-Marín B. Concentración inadecuada de cloro residual libre en agua de hogares de Lima Metropolitana, 2016. Rev Peru Med Exp Salud Publica. 2018;35(2): 347-8. doi: 10.17843/rpmesp.2018.352.3648. niveles residuales de cloro por debajo de $0,5 \mathrm{mgL}^{-1}$ de cloro. Se empleó los datos de longitud y latitud de los centroides de los conglomerados de hogares para proyectarlos sobre un mapa de base de OpenStreetMap y realizar un análisis de Kernel con especificaciones predeterminadas en ArcGIS versión 10.5 (ESRI Inc., Redlands, CA, USA).

Se incluyó un total de 3345 hogares con datos completos sobre abastecimiento y niveles residuales de cloro, representando un total expandido de 2182805 hogares. El abastecimiento de agua por red pública provenía de dentro del hogar en el 96,6\% ponderado (expandido: 2108060 hogares) y de fuera del hogar en el $3,4 \%$ ponderado (expandido: 74745 hogares). En relación al acceso a agua clorada, se encontró una concentración inadecuada de cloro residual libre en un tercio de los hogares (expandido:74 2389 hogares; $34,0 \%$ ponderado). El análisis Kernel se hizo sobre los 1123 centroides de conglomerados de hogares con niveles de cloro residual inadecuado. La Figura $1 \mathrm{~A}$ muestra dos zonas con alta densidad de conglomerados muestrales de hogares con acceso a agua con niveles inadecuados de cloro residual (áreas rojas), estando una de ellas en los alrededores del Cercado de Lima y La Victoria (Figura 1B), y la otra, en el distrito de Pueblo Libre (Figura 1C); así como también se identificó una área de densidad intermedia (área naranja) sobre el distrito de Bellavista (Figura 1C). Si bien el análisis identificó zonas con diferentes densidades en Lima Metropolitana, es de resaltar que los hogares con inadecuados niveles de cloro se distribuyen por toda la ciudad (Figura 1A).

Sobre el acceso al agua segura, dentro de las metas de los Objetivos del Desarrollo Sostenible propuestas por las Naciones Unidas y asumidas como compromiso por el Perú, se espera para el 2030 garantizar la disponibilidad universal y la gestión sostenible del agua y saneamiento para toda persona ${ }^{(5)}$. El acceso al agua por red pública ha incrementado en el país en los últimos años, siendo este incremento marcado en las zonas rurales y en departamentos de las regiones sierra y selva del país ${ }^{(6)}$. A pesar de ello, encontramos que un tercio de los hogares limeños presentó niveles de cloración de agua menores a los requeridos por la normatividad vigente.

En línea con la meta propuesta para el 2030, se debe garantizar el derecho al acceso a agua segura, estrategia reconocida costo-efectiva para la disminución de enfermedades y mortalidad. Por ello, el incremento en el acceso al agua de distribución pública y los retos que esta actividad demanda, debe acompañarse de un estricto control de la calidad del agua en toda la red de distribución, particularmente del monitoreo del nivel de cloración del agua a nivel de los hogares con el objetivo de seguir mejorando los indicadores de salud de nuestro país.

Fuentes de financiamiento: autofinanciado.

Conflictos de interés: los autores declaran no tener conflictos de interés. 


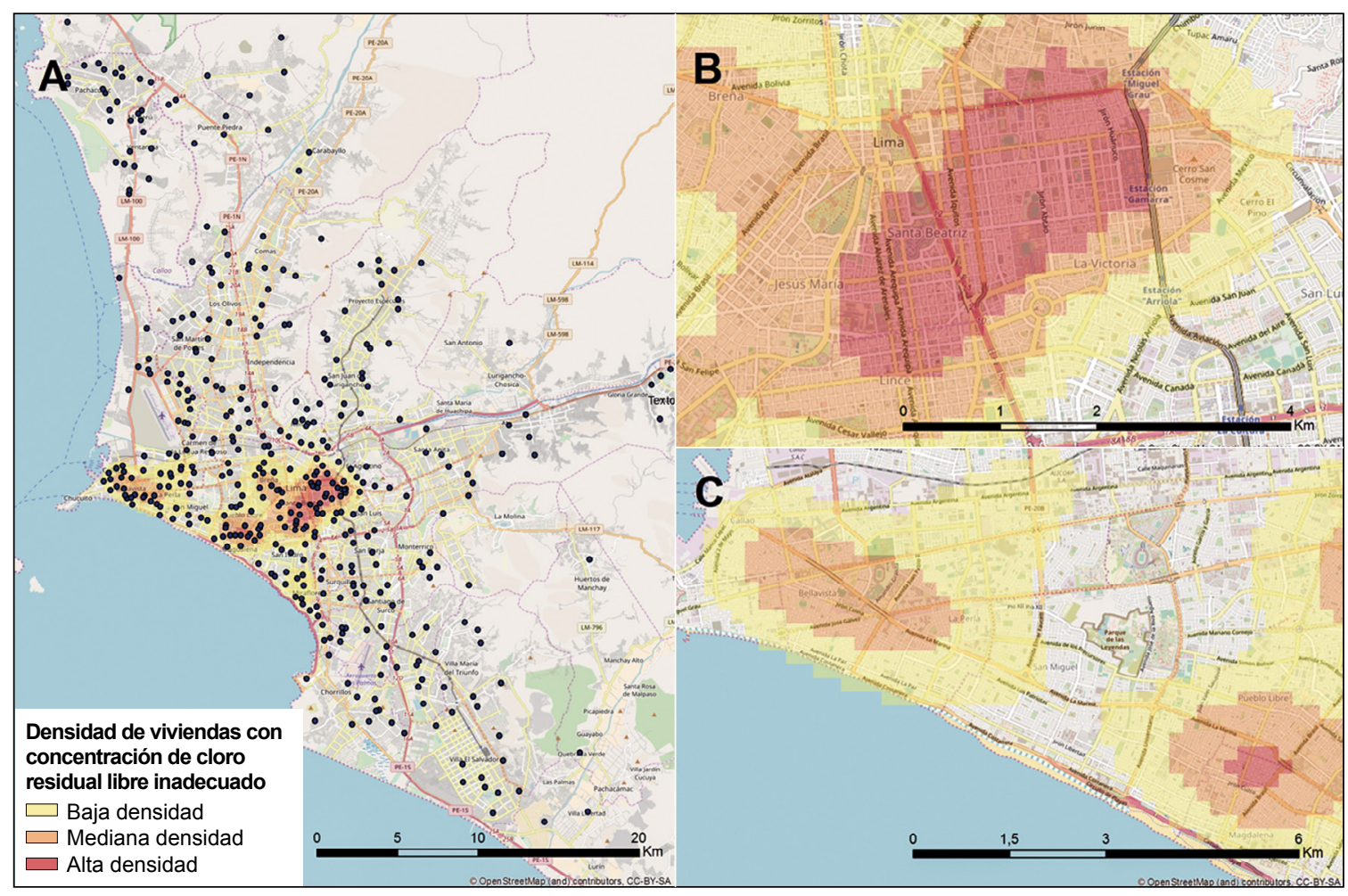

Figura 1. Análisis de densidad Kernel de centroides de conglomerados georeferenciados de hogares con abastecimiento de agua con cloro residual libre inadecuado en Lima Metropolitana, ENAHO 2016. (A) Los puntos representan los centroides de conglomerados de hogares en Lima Metropolitana (B) Conglomerado de alta densidad en Cercado de Lima y La Victoria (C) Conglomerado de alta densidad en Pueblo Libre.

\section{REFERENCIAS BIBLIOGRÁFICAS}

1. United Nations [Internet]. The Human Right to Water and Sanitation [citado el 10 de septiembre de 2018]. Disponible en: http://www.un.org/waterforlifedecade/pdf/human_right_to water_and_sanitation_media_brief.pdf.

2. Ministerio de Salud [Internet]. Reglamento de la Calidad del Agua para Consumo Humano. Decreto Supremo N 031-2010-SA. Lima, Perú [citado el 12 de abril de 2018]. Disponible en: http:// www.digesa.minsa.gob.pe/publicaciones/descargas/Reglamento_ Calidad_Agua.pdf.

3. Instituto Nacional de Estadística e Informática (INEI) [Internet]. Perú - Encuesta Nacional de Hogares sobre Condiciones de Vida y Pobreza 2016 [citado el 03 abril de 2018]. Disponible en https:// webinei.inei.gob.pe/anda_inei/index.php/catalog/543/vargrp/ VG11

4. World Health Organization (WHO) [Internet]. Drinking-Water Geneva, Switzerland: WHO; 2018 [citado el 03 de abril de 2018]. Disponible en: http://www.who.int/mediacentre/factsheets/fs391/en/.

5. Instituto Nacional de Estadística e Informática (INEI) [Internet]. Perú: Sistema de monitoreo y seguimiento de los indicadores de los objetivos de desarrollo sostenible [citado el 03 de marzo de 2018]. Disponible en: https://ods.inei.gob.pe/ods/.

6. Instituto Nacional de Estadística e Informática (INEI) [Internet]. Perú: formas de acceso al agua y saneamiento básico. Síntesis Estadística [citado el 01 de marzo de 2018]. Disponible en: https://www.inei. gob.pe/media/MenuRecursivo/boletines/boletin_agua.pdf.

Correspondencia: Guido Jean Pierre Bendezu Quispe

Dirección: Avenida Salaverry 1230, Jesús María. Lima, Perú

Teléfono: $(+51) 959615377$

Correo electrónico:guidobq@gmail.com

\section{PRIMERA EVIDENCIA DE Aedes aegypti EN LA REGIÓN DE AREQUIPA, PERÚ 2016}

\section{FIRST EVIDENCE OF Aedes aegypti IN THE AREQUIPA REGION, PERÚ 2016}

\author{
Edwin Requena-Zúñiga ${ }^{1, a}$, Fernando Málaga-Chávez ${ }^{2, a}$, \\ Evertson A. Ricardo León Tito ${ }^{2, a}$, Rosario Balta-León ${ }^{1, a}$, \\ Jorge Valle-Toledo ${ }^{1, a}$
}

Sr. Editor. En 1984, se confirma la reintroducción de Ae. aegypti en el Perú ${ }^{(1)}$. En el 2000 se reporta su presencia en la ciudad de Lima ${ }^{(2)}$, luego en 2015 se registró la presencia de $A$. aegypti al sur de Lima en el distrito de Parcona en la ciudad de lca después de la sospecha de un probable caso de dengue autóctono ${ }^{(3)}$. En 2016 se reporta un brote de dengue en el distrito de Parcona mientras que el vector continuaba

\footnotetext{
Laboratorio de Entomología, Instituto Nacional de Salud. Lima, Perú.

2 Dirección Regional de Salud de Arequipa, Dirección Ejecutiva de Salud Ambiental. Lima, Perú.

Biólogo

Recibido: 20/03/2018 Aprobado: 28/03/2018 En línea: 15/05/2018
}

Citar como: Requena-Zúñiga E, Málaga-Chávez F, León Tito EAR, Balta-León R, Valle-Toledo J. Primera evidencia de Aedes aegypti en la región de Arequipa, Perú 2016. Rev Peru Med Exp Salud Publica. 2018;35(2): 348-9. doi: 10.17843/ rpmesp.2018.352.3557 